\title{
Comorbidity of post traumatic stress disorder, attention deficit with hyperactivity, conduct, and oppositional defiant disorder in Palestinian children affected by war on Gaza
}

\author{
Abdelaziz M. Thabet ${ }^{1^{\star}}$, Ahmad Abu Tawahina ${ }^{2}$, Eyad El Sarraj ${ }^{2}$ David Henely $^{3}$, \\ Henrick Pelleick ${ }^{3}$, Panos Vostanis ${ }^{4}$ \\ ${ }^{1}$ Alquds University, Gaza, Palestine; *Corresponding Author: abdelaziz.thabet@gmail.com \\ ${ }^{2}$ Gaza Community Mental Health Programme, Gaza, Palestine \\ ${ }^{3}$ Uppsala University, Uppsala, Sweden \\ ${ }^{4}$ University of Leicester, Greenwood Institute of Child Health, Leicester, UK
}

Received 11 October 2012; revised 5 March 2013; accepted 15 April 2013

Copyright (c) 2013 A. M. Thabet et al. This is an open access article distributed under the Creative Commons Attribution License, which permits unrestricted use, distribution, and reproduction in any medium, provided the original work is properly cited.

\section{ABSTRACT}

Aim: The aim of this study was to investigate the impact of war on children and comorbidity of post traumatic stress disorder, attention deficit with hyperactivity, conduct, and oppositional defiant disorder in Palestinian children. Methods: The study was conducted in the entire Gaza Strip 6 months after the end of the war on Gaza that lasted for 23 days. The study sample included 410 children aged 6 to 17 years. Children completed measures of experience of traumatic events (Gaza Traumatic Checklist-War on Gaza), post traumatic stress disorder index, attention deficit with hyperactivity scale for parents and self, conduct disorder scale, and oppositional defiant disorder. Results: Palestinians children investigated 6 months after the war on Gaza still reported traumatic experiences: $94.6 \%$ heard the sonic sounds of the jet fighters, $91.7 \%$ heard shelling of the area by artillery, $92 \%$ watched mutilated bodies on television, $80 \%$ were deprived from water or electricity during the war, $50.7 \%$ said they left home for safer place. Using Diagnostic Manual of Mental Disorders-IV (DSMIV) criteria for post traumatic stress disorder, $25.1 \%$ of children reported no psychological reactions, $25.9 \%$ of children reported one criteria, $39.3 \%$ of children reported partial post traumatic stress disorder and $\mathbf{9 . 8 \%}$ of children reported full criteria for post traumatic stress disorder. According to the parents' report, the results showed $31.3 \%$ of children met the criteria for inattentive type, $36.3 \%$ of children were impulsive and $29 \%$ met criteria for combined type. According to the children's report, the results showed $\mathbf{2 8 . 8 \%}$ of children met the criteria for inattentive type, $37.3 \%$ of children were impulsive and $28.3 \%$ met criteria for combined type. Using DSM-IV diagnostic criteria of conduct disorder and oppositional defiant disorder, the study showed that $38.1 \%$ of parents reported conduct disorder in their children and $46.3 \%$ reported oppositional defiant disorder. While $39.3 \%$ of children themselves reported conduct disorder and $44 \%$ of them reported oppositional defiant disorder. The study showed that $5.1 \%$ of children had comorbidity of post traumatic stress disorder and attention deficit disorder, $4.4 \%$ had comorbidity of post traumatic stress disorder and impulsivity-hyperactivity disorder, and $4.4 \%$ had comorbidity of post traumatic stress disorder and attention deficit with hyperactivity combined type. Also, $4.6 \%$ of children had comorbidity of conduct and post traumatic stress disorder and $6.1 \%$ had comorbidity of oppositional defiant disorder and post traumatic stress disorder. Conclusions: This study revealed that children living in areas of conflict and war are the main group at risk of developing post traumatic stress disorder and other behavioral problems including attention deficit with hyperactivity, conduct, and oppositional defiant disorder, 
and the internationallaws must protect the civilians during the conflict, establishing safe havens for children and their families to decrease the effect of war on children.

\author{
Keywords: War on Gaza; Comorbidity; Post \\ Traumatic Stress Disorder; Attention Deficit with \\ Hyperactivity; Conduct; Oppositional Defiant \\ Disorder
}

\section{INTRODUCTION}

Gaza Strip is one of the war area and conflict for the last 4 decades. Palestinian children exposed to repeated incursions of the border areas with many causalities in children and their families. The last war on Gaza was one of the last and not least types of collective trauma of a nation.

At the end of December 2008, two days after the ending of the truce in the area, the Israeli occupying forces conducted sudden and intensive air strikes on the entire Gaza Strip. These attacks destroyed most of the Gaza security offices including police stations. As a result, immediately, more than 230 Palestinians were killed and at least 770 were injured including 100 in critical condition. This military operation continued for 23 days. As a result, 1420 Palestinians, including 446 children and 110 women and 108 elderly, were killed and 5320 others, including 1855 children and 795 women, were injured. This did not mean that the rest of the fatalities and injuries were engaged in hostilities, or that they were not innocent civilians. A large number of men and male youth were killed in their homes in the presence of their families. Its phases resulted in a mass destruction of private properties. At least 4000 houses were totally destroyed and another 16,000 houses were partially damaged [1].

Many studies conducted in the areas of war and conflict found high rates of PTSD, depression, and anxiety among children living in such areas. Previous studies conducted in the Palestinian area showed the rate of post traumatic stress reactions ranged from $40 \%$ to $71 \%$, and anxiety rates ranged from $21 \%$ to $69.9 \%$ in children and adolescents [2-5]. Epidemiological studies conducted in various countries have revealed prevalence rates of attention deficit with hyperactivity ranging from $4 \%$ to $12 \%$ in the general population of children between the ages of 6 and 12 (10.3\% when using DSM III-R diagnostic criteria), with a higher frequency among boys than girls [6]. Oppositional defiant disorder is the most common comorbid condition associated with attention deficit with hyperactivity both in the outpatient clinical setting and in the general population [7-11]. Few studies had been conducted in the area, however, in a new study to establish the prevalence and distribution of attention deficit- hyperactivity disorder symptoms and other associated comorbid mental health problems in Palestinian schoolchildren. Thus 349 children aged 6 - 15 years were randomly selected from 23 schools in Gaza and the West Bank and were rated by their parents and teachers using both the attention deficit with hyperactivity DSM-IV checklist and the Strengths and the Difficulties Questionnaire, which also measured conduct and emotional problems. There was a significant agreement between parents and teachers, with $4.3 \%$ of the children rated above the established cut-off scores on both the parent and teacher DSM-IV Checklist. Male gender, family size and living in an area of socioeconomic deprivation were independently associated with attention deficit with hyperactivity symptoms [6].

A number of clinically based studies have reported on a high rate of comorbidity associated problems in AttenTion-Deficit Hyperactivity Disorder (ADHD) [12]. The most common types of comorbidities reported have been oppositional defiant disorder, conduct disorder, affective and anxiety disorders, and specific learning disorders including reading disability and developmental coordination disorder (DCD). Comorbidity in child psychiatry is one of the debate issues, it is important to consider findings on the comorbidity of different psychiatric disorders in children victims of war and conflict.

Also, comorbidity of post traumatic stress disorder and depression among children was exposed to trauma from war and other sources of life threat and adversities, in the absence of the confounding (social adversity) factors faced by children in war zones and refugee [13-16].

Several studies had linked Attention-Deficit/Hyperactivity Disorder (ADHD) to post traumatic stress disorder. Others, in their studies found an association between attention-deficit hyperactivity disorder and post traumatic stress disorder that was largely due to overlapping symptomatology —in particular hyperarousal and hypervigilance symptoms - and suggested that patients with attention-deficit hyperactivity disorder should be screened for post traumatic stress disorder (PTSD) as a differential diagnosis [17]. This view was supported by [18] who commented on the high degree of symptom overlap and comorbidity between the two disorders. In a study of 117 severely maltreated children, 35\% met criteria for post traumatic stress disorder. Attention-deficit hyperactivity disorder was found to be a concurrent condition in $37 \%$ with post traumatic stress disorder, whereas attention-deficit hyperactivity disorder was found to be a comorbid condition in only $17 \%$ of the remaining without post traumatic stress disorder [19].

In another study examining the relationship between attention-deficit hyperactivity disorder and post traumatic stress disorder, they found that abused children with PTSD had significantly higher levels of activity 
than both non-abused children and abused children without post traumatic stress disorder [20]. Others in their studies of 99 delinquent 13 to 19-year-old boys with conduct disorder and found that both attention-deficit hyperactivity disorder and post traumatic stress disorder existed at higher rates among those who were depressed compared to the non-depressed controls [21]. The aim of the study was to investigate the effect of trauma on Palestinian children mental health problems such as post traumatic stress disorder, attention deficit with hyperactivity disorder, oppositional defiant disorder, and conduct disorder and comorbidity between the different psychiatric disorders.

\section{METHOD}

\subsection{Participants and procedure}

The participants were 410 Palestinian children, 224 were boys (54.6\%) and 186 girls were girls living in Gaza Strip. They were 8 - 18 years old $(M=12.93 \pm 3.87)$, and there were no gender differences according to age $(F(1,384)=0.42, p=n s)$. The original sample consisted of 410 children and no drop out during the interviews in their homes.

The sample was randomly selected from the population census representing the five areas of the Gaza Strip. In selecting the children each area was divided into blocks and from each block one street was chosen, and from each street every 10th home was approached for the data collection. The field work was conducted by professionals who had experiences in working with children and families. They were 5 mental health workers. They were trained for research and data collection, and they visited the families according to prepared lists of number of children selected to the study. The field workers presented an information letter to the parents, and if agreed, they obtained a written permission for their children's participation. Children were interviewed individually in their homes and each interview lasted approximately 30 minutes. The interviewers informed children that there were no right or wrong answers, provided guidance in filling-up the scales. Children and parents were also informed that that they were free to withdraw from the study at any time. The data collection was done between May and June 2009.

\subsection{Instruments}

- Sociodemographic information was collected from parents and information about traumatic events, mental health and resilience from children themselves.

- Traumatic experiences was collected using War on Gaza Traumatic Events Checklist [6] was used, describing the most common traumatic experiences adolescents could have faced in the Gaza Strip during the last war on Gaza, including shelling of their area of residence, internal displacement. The checklist was revised from a version used in earlier research, adapted for the nature of traumatic events occurring during the current period. The checklist consisted of 25 items with answer with yes (1) and no (0). The scoring of the scale is considered by summing all the answers. The internal consistency of the scale calculated using Cronbach's Alpha, was $\alpha=0.80$ and split half was 0.68 .

Post traumatic stress disorder Index for DSM-IV: Adolescent Version [22].

The items of the post traumatic stress disorder index are keyed to DSM-IV criteria and can provide preliminary post traumatic stress disorder diagnostic information. Self-reports for children and adolescents exist, as well as a parent report of post traumatic stress disorder symptoms. The adolescent version (for adolescent aged 13 years and older) contains a total of 22 questions, have also been administered in school classroom settings. A 5-point Likert scale from 0 (none of the time) to 4 (most all the time) is used to rate post traumatic stress disorder symptoms. The structure of the measure facilitates scoring. The first 18 questions on the child and adolescent version, and the first 19 questions on the parent version, assess for DSM-IV post traumatic stress disorder Criterion $\mathrm{B}, \mathrm{C}$, and $\mathrm{D}$ symptoms, three separate scores were computed from these 20 items for intrusive symptoms (Criterion B), avoidance symptoms (Criterion C), and hyperarousal symptoms (Criterion D). Questions 13-19 assess Criterion A1, and 20-22 assess for Criterion A2. The internal consistency of the Arabic version of the post traumatic stress disorder Adolescent Reaction Index was highly satisfactory (Cronbach's Alpha $=0.88$ ) and split half was 0.82 . In this study the reliability of the scale using Cronbach's Alpha was 0.85 and split half was 0.82 .

- Attention Deficit Hyperactivity disorder was collected using Structured Clinical Interview of mothers and fathers for DSM-IV diagnosis of attention-deficit hyperactivity disorder [23], Arabic version [6].

This interview consisted of 18 items questionnaire, based on DSM-IV diagnostic criteria for attention-deficit hyperactivity disorder in children. Children scored six and above in inattentive nine items are considered as inattentive; the scoring is $0=$ no and $1=$ yes, children reported 6 and more in hyperactivity-impulsive 9 items are considered hyperactive-impulsive. The combined type is rate by summing both inattentive and hyperactive-impulsive scores. This scale was validated by The Arabic version of this scale was used in which the translation and back translation had been conducted and the Arabic Version was send to panel of expert for validity. The five experts agreed on all items and no changes were done. In study by [6], for parents scale, internal consis- 
tency of the scale, calculated using Cronbach's Alpha was also high (0.84); the split half reliability of the scale was (0.79). While, for teachers, internal consistency of the scale, calculated using Cronbach's Alpha was (0.87); the split half reliability of the scale was (0.84) [6]. For this study, internal consistency of scale for parents form, using Cronbach's Alpha was 0.89 and split half was 0.76 . While Cronbach's Alpha for the children scale was 0.89 and split half was 0.77 .

- Conduct disorder was measured using Conduct Disorder questionnaire DSM-IV diagnosis of (23). This scale consisted of 15 items, based on DSM-IV diagnostic criteria for conduct disorder in children. Children scored 3 symptoms and above are considered as a case of conduct disorder. The Arabic version of this scale was used in which the translation and back translation had experts agreed on all items and no changes were done. In this study for parents scale, internal consistency of the scale, calculated using Cronbach's Alpha was high (0.83); the split half reliability of the scale was (0.58). While, for students, internal consistency of the scale, calculated using Cronbach's Alpha was (0.84); the split half reliability of the scale was (0.61).

Oppositional defiant disorder was measured using Oppositional defiant disorder questionnaire DSM-IV diagnosis of attention deficit with hyperactivity [23]. This scale consisted of 9 items, based on DSM-IV diagnostic criteria for children. Children scored 3 symptoms and above are considered as a case of Oppositional defiant conduct disorder. The Arabic version of this scale was used in which the translation and back translation had been conducted and the Arabic version was send to panel of experts for validity. The five experts agreed on all items and no changes were done. In this study for parents scale, internal consistency of the scale, calculated using Cronbach's Alpha was high (0.79); the split half reliability of the scale was (0.75). While, for students, internal consistency of the scale, calculated using Cronbach's Alpha was (0.80); the split half reliability of the scale was (0.74).

\section{STATISTICAL ANALYSIS}

The statistical analyses were accomplished with the SSPS for Windows (Version 17).

Percentages, means and standard deviations were used to characterize the sample of children. The T-test, oneway analysis of variance and post hoc Tukey's T-test were used to test both the differences in means of posttraumatic stress disorder, attention deficit with hyperactivity disorder, oppositional defiant disorder, and conduct disorder and comorbidity between the different psychiatric disorders. Associations between the means of vari- ables were measures using Spearman correlation coefficient test.

\section{RESULTS}

\subsection{Sociodemographic Characteristic of the Study}

The sample responded to the interview were 410 participants with response rate of $100 \%$, it consisted of 224 males (54.6\%) and 186 girls (45.4\%). The age ranged from 8 - 18 years with mean age was 12.93 years $(\mathrm{SD}=$ 3.87). According to place of residence $21 \%$ of children were from North Gaza, 28.8\% were from Gaza, 14.4\% were from Middle area, 18.3\% were from Khan Younis, and 17.\% were from Rafah area (south of Gaza). According to type of residence, $43.5 \%$ of children live in cities, $12.5 \%$ live in villages, and $44 \%$ live in camps. According to number of siblings, $13.6 \%$ of families had less than 4 children, $61.4 \%$ had 5 - 7 children, and 25\% had 8 and more siblings. In looking for the family monthly income, $60.9 \%$ of the families monthly income was less than 350 US \$ per month, 30.4\% earned 351 700 US \$, and only 8.7\% earned more than 701 US \$ (Table 1).

\subsection{Types of Traumatic Events}

Palestinians children investigated 6 months after war on Gaza still reported traumatic experiences: $94.6 \%$ hear the sonic sounds of the jetfighters, 91.7\%, hear shelling of the area by artillery, 92\% watched mutilated bodies in TV, $80 \%$ were deprived from water or electricity during the war, $50.7 \%$ said they left home form more safe place (Table 2).

\subsection{Sex Differences in Traumatic Events}

Children reported from no events to 24 traumatic events, mean traumatic events was 8.48 (SD = 3.96). The results showed that mean traumatic events reported by males was 8.69 (SD =3.92) compared to mean in female $=8.22(\mathrm{SD}=4.00)$. No significant differences between males and females in reporting traumatic events $(t=1.18$, $\mathrm{p}=0.23)$.

\subsection{Relationship between Trauma and Post Traumatic Stress Disorder}

Using Pearson correlation test, the study showed that there were statistically significant correlation between total traumatic events and total post traumatic stress disorder $(r=0.29, p=0.001)$.

\subsection{Prevalence of Post Traumatic Stress Disorder}

The results showed that mean post traumatic stress 
Table 1. Sociodemographic characteristic of the study sample.

\begin{tabular}{|c|c|c|}
\hline Sex & No. & $\%$ \\
\hline Boys & 224 & 54.6 \\
\hline Girls & 186 & 45.4 \\
\hline \multicolumn{3}{|l|}{ Address } \\
\hline North Gaza & 86 & 21 \\
\hline Gaza & 118 & 28.8 \\
\hline Middle area & 59 & 14.4 \\
\hline Khan Younis & 75 & 18.3 \\
\hline Rafah area & 72 & 17.6 \\
\hline \multicolumn{3}{|l|}{ Number of siblings } \\
\hline Less than 4 & 115 & 28 \\
\hline 5 - 7 children & 190 & 46.3 \\
\hline 8 and above & 104 & 25.4 \\
\hline \multicolumn{3}{|l|}{ Monthly family income } \\
\hline Less than 300 US \$ & 253 & 61.7 \\
\hline From 301 - 650 US \$ & 102 & 24.9 \\
\hline More than 651 US \$ & 55 & 13.4 \\
\hline \multicolumn{3}{|l|}{ Paternal education } \\
\hline Uneducated & 21 & 5.1 \\
\hline Preparatory & 59 & 14.4 \\
\hline Primary & 86 & 21 \\
\hline Secondary & 121 & 29.5 \\
\hline Diploma & 21 & 5.1 \\
\hline University & 84 & 20.5 \\
\hline High education & 18 & 4.4 \\
\hline \multicolumn{3}{|l|}{ Father work } \\
\hline Unemployed & 114 & 27.8 \\
\hline Simple worker & 71 & 17.3 \\
\hline Skilled worker & 27 & 6.6 \\
\hline Skilled worker & 135 & 32.9 \\
\hline Merchant & 30 & 7.3 \\
\hline Others & 33 & 8 \\
\hline \multicolumn{3}{|l|}{ Maternal education } \\
\hline Uneducated & 32 & 7.8 \\
\hline Preparatory & 39 & 9.5 \\
\hline Primary & 95 & 23.2 \\
\hline Secondary & 181 & 44.1 \\
\hline Diploma & 28 & 6.8 \\
\hline University & 35 & 8.5 \\
\hline \multicolumn{3}{|l|}{ Maternal work } \\
\hline Housewives & 378 & 92.2 \\
\hline Simple worker & 6 & 1.5 \\
\hline Employee & 19 & 4.6 \\
\hline
\end{tabular}

disorder reactions was (20 items of the 22) was 28.50 $(\mathrm{SD}=13.37)$, intrusion symptoms mean was $9.0(\mathrm{SD}=$
4.77), avoidance mean was 7.33 (SD = 4.55), and hyperarousal mean was $8.7(\mathrm{SD}=4.5)$. In order to find the differences in post traumatic stress disorder according to sex, $\mathrm{t}$ independent test was done. The results showed that there was no significant difference between boys and girls in total PTS reactions and other subscale $(\mathrm{t}=0.53$, $\mathrm{p}$ $=\mathrm{ns}$ ). Using DSM-IV criteria for post traumatic stress disorder, 25.1\% showed no psychological reactions, $25.9 \%$ of children reported one criteria, $39.3 \%$ of children reported partial post traumatic stress disorder and $9.8 \%$ of children reported full criteria for post traumatic stress disorder (Table 3).

Table 2. Types of traumatic events.

\begin{tabular}{|c|c|c|c|}
\hline \multicolumn{2}{|r|}{ Trauma } & \multirow{2}{*}{ No. } & \multirow{2}{*}{$\frac{\%}{94.6}$} \\
\hline 1. & Heard the sonic sounds of the jetfighters & & \\
\hline 2. & Heard shelling of the area by artillery & 376 & 91.7 \\
\hline 3. & Watched mutilated bodies in television & 337 & 92 \\
\hline 4. & $\begin{array}{l}\text { Deprivation from water, food, or electricity } \\
\text { during the war home }\end{array}$ & 328 & 80 \\
\hline 5. & Shot by bullets, rocket, or bombs & 292 & 71.2 \\
\hline 6. & Forced to leave your home during the war & 208 & 50.7 \\
\hline 7. & Heard killing of non relative & 185 & 45.1 \\
\hline 8. & Threaten by shooting & 178 & 43.4 \\
\hline 9. & $\begin{array}{l}\text { Witnessed firing by tanks and heavy artillery } \\
\text { at neighbors homes }\end{array}$ & 159 & 29.8 \\
\hline 10. & Detained for hours during the war & 125 & 30.5 \\
\hline 11. & Witnessed of a friend home demolition & 122 & 29.8 \\
\hline 12. & $\begin{array}{l}\text { Destruction of personal belongings during } \\
\text { incursion }\end{array}$ & 101 & 24.6 \\
\hline 13. & Witnessed killing of non relative & 82 & 20 \\
\hline 14. & $\begin{array}{l}\text { Witnessed firing by tanks and heavy artillery } \\
\text { at own home }\end{array}$ & 75 & 18.3 \\
\hline 15. & Witnessed shooting of a friend & 74 & 18 \\
\hline 16. & Witnessed killing of a relative & 66 & 16.1 \\
\hline 17. & Witnessed shooting of a relative & 59 & 14.4 \\
\hline 18. & Heard killing of a relative & 49 & 12 \\
\hline 19. & $\begin{array}{l}\text { Beaten and humiliation by the army during } \\
\text { the war }\end{array}$ & 44 & 10.7 \\
\hline 20. & $\begin{array}{l}\text { Exposure to burn by bombs and phosphorous } \\
\text { bombs }\end{array}$ & 43 & 10.5 \\
\hline 21. & $\begin{array}{l}\text { Witnessed shelling and destruction of own } \\
\text { home }\end{array}$ & 42 & 10.2 \\
\hline 22. & Witnessed assassination of people by rockets & 42 & 10.2 \\
\hline 23. & Threaten with being killed & 42 & 10.3 \\
\hline 24. & $\begin{array}{l}\text { Physical injury due to bombardment of own } \\
\text { home }\end{array}$ & 35 & 8.5 \\
\hline 25. & $\begin{array}{l}\text { Threatened with death by being used as } \\
\text { human shield by the army to move from one } \\
\text { home to home }\end{array}$ & 28 & 6.8 \\
\hline
\end{tabular}


Table 3. Prevalence of post traumatic stress disorder.

\begin{tabular}{cc}
\hline & $\%$ \\
\hline $\begin{array}{c}\text { No post traumatic stress disorder } \\
\text { One criteria of post traumatic stress disorder } \\
\text { (B, or C, or D) }\end{array}$ & 25.1 \\
$\begin{array}{c}\text { Partial post traumatic stress disorder } \\
\text { (B and C or B and C or C and D) }\end{array}$ & 25.9 \\
Full criteria of post traumatic stress disorder & 39.3 \\
\hline
\end{tabular}

\subsection{Prevalence of Attention Deficit with Hyperactivity According to Parent}

According to parents report, the results showed 31.3\% of children met the DSM-IV criteria for inattentive type $36.3 \%$ of children was impulsive, and $29 \%$ met criteria for combined type.

\subsection{Prevalence of Attention Deficit with Hyperactivity According to Children}

According to children report, the results showed 28.8\% of children met the DSM-IV criteria for inattentive type $37.3 \%$ of children was impulsive, and $28.3 \%$ met criteria for combined type (Table 4).

\subsection{Prevalence of Conduct and Oppositional Defiant Disorders}

Using DSM-IV diagnostic criteria of conduct disorder and oppositional defiant disorder, the study showed that $38.1 \%$ of parents reported conduct disorder in their children and $46.3 \%$ reported oppositional defiant disorder. While $39.3 \%$ of children themselves reported conduct disorder and $44 \%$ of them reported oppositional defiant disorder (Table 5).

\subsection{Comorbidity of PTSD, Attention Deficit with Hyperactivity, Conduct, and Oppositional Defiant Disorder According to Parents}

The study showed that 21 children (5.1\%) had comorbidity of post traumatic stress disorder and attention deficit disorder $\left(\chi^{2}=10.1, \mathrm{p}<0.01\right), 18$ children $(4.4 \%)$ had comorbidity of post traumatic stress disorder and impulsivity-hyperactivity $\left(\chi^{2}=2.3\right.$, $\left.\mathrm{p}<\mathrm{Ns}\right)$, and 18 children $(4.4 \%)$ had comorbidity of post traumatic stress disorder and attention deficit with hyperactivity combined type $\left(\chi^{2}=5.4\right.$, p $\left.<0.01\right)$. Also $4.6 \%$ of children had comorbidity of conduct and post traumatic stress disorder $\left(\chi^{2}=1.77, \mathrm{p}<0.01\right)$ and $6.1 \%$ had comorbidity of oppositional defiant disorder and post traumatic stress disorder $\left(\chi^{2}=4.3\right.$, $\left.\mathrm{p}<0.01\right)$ (Table 6).
Table 4. Prevalence of attention deficit with hyperactivity disorder according to parents and children.

\begin{tabular}{ccccc}
\hline & \multicolumn{2}{c}{ Parent } & \multicolumn{2}{c}{ Child } \\
\cline { 2 - 5 } & Yes & No & Yes & No \\
\hline Inattention & 31.3 & 68.7 & 28.8 & 71.2 \\
Hyperactivity & 36.3 & 63.7 & 37.3 & 62.7 \\
Attention deficit with hyperactivity & 29 & 71 & 28.3 & 71.7 \\
\hline
\end{tabular}

Table 5. Prevalence of conduct and oppositional defiant disorders.

\begin{tabular}{ccccc}
\hline Behavioural disorders & \multicolumn{2}{c}{ Parent } & \multicolumn{2}{c}{ Child } \\
\hline & Yes & No & Yes & No \\
\hline Conduct disorder & 38.1 & 61.9 & 39.3 & 60.1 \\
Oppositional defiant disorder & 46.3 & 53.7 & 44 & 56 \\
\hline
\end{tabular}

Table 6. Comorbidity of post traumatic stress disorder, attention deficit with hyperactivity disorder, conduct, and opposetional defiant disorder according to parents.

\begin{tabular}{|c|c|c|c|c|c|}
\hline & \multicolumn{2}{|c|}{$\begin{array}{l}\text { No post traumatic } \\
\text { stress disorder }\end{array}$} & \multicolumn{2}{|c|}{$\begin{array}{l}\text { post traumatic } \\
\text { stress disorder }\end{array}$} & \multirow[t]{2}{*}{$\chi^{2}$} \\
\hline & No. & $\%$ & No. & $\%$ & \\
\hline Attention deficit & 107 & 26.2 & 21 & 5.1 & ${ }^{* *} 10.1$ \\
\hline Hyperactivity-impulsivity & 130 & 31.9 & 18 & 4.4 & 2.23 \\
\hline $\begin{array}{l}\text { Attention deficit disorder } \\
\text { with hyperactivity }\end{array}$ & 101 & 24.6 & 18 & 4.4 & ${ }^{* *} 5.4$ \\
\hline Conduct disorder & 136 & 33.2 & 19 & 4.6 & 1.77 \\
\hline $\begin{array}{l}\text { Oppositional defiant } \\
\text { disorder }\end{array}$ & 167 & 40.7 & 25 & 6.1 & ${ }^{* *} 4.3$ \\
\hline
\end{tabular}

\subsection{Comorbidity of Post Traumatic Stress Disorder Attention Deficit with Hyperactivity, Conduct, and Attention Deficit with Hyperactivity According to Children}

The study showed that 15 children (3.7\%) had comorbidity of post traumatic stress disorder and attention deficit disorder $\left(\chi^{2}=1.85, \mathrm{p}<\mathrm{ns}\right), 16$ children $(3.9 \%)$ had comorbidity of post traumatic stress disorder and impulsivity-hyperactivity $\left(\chi^{2}=3.9, \mathrm{p}<\mathrm{ns}\right)$, and 22 children $(5.4 \%)$ had had comorbidity of post traumatic stress disorder and attention deficit with hyperactivity combined type $\left(\chi^{2}=5.9\right.$, $\left.\mathrm{p}<0.01\right)$. Also $4.4 \%$ of children had comorbidity of conduct and post traumatic stress disorder ( $\chi^{2}=0.44, \mathrm{p}<\mathrm{ns}$ ) and 5.1\% had comorbidity of attention deficit with hyperactivity and post traumatic stress disorder $\left(\chi^{2}=1.1, \mathrm{p}<\mathrm{ns}\right)$ (Table 7). 
Table 7. Comorbidity of post traumatic stress disorder, attention deficit with hyperactivity disorder, conduct, and opposetional defiant disorder according to children.

\begin{tabular}{|c|c|c|c|c|c|}
\hline & \multicolumn{2}{|c|}{$\begin{array}{c}\text { No post } \\
\text { traumatic stress } \\
\text { disorder }\end{array}$} & \multicolumn{2}{|c|}{$\begin{array}{l}\text { Post traumatic } \\
\text { stress disorder }\end{array}$} & \multirow[t]{2}{*}{$\mathrm{X} 2$} \\
\hline & $\mathbf{N}$ & $\%$ & $\mathbf{N}$ & $\%$ & \\
\hline Attention deficit disorder & 102 & 24.9 & 16 & 3.9 & 2.7 \\
\hline Hyperactivity-impulsivity & 131 & 32 & 22 & 5.4 & ** 5.9 \\
\hline $\begin{array}{l}\text { Attention deficit } \\
\text { with hyperactivity }\end{array}$ & 101 & 24.6 & 15 & 3.7 & 1.85 \\
\hline Conduct disorder & 146 & 35.7 & 18 & 4.4 & $/ / 0.44$ \\
\hline $\begin{array}{l}\text { Oppositional defiant } \\
\text { disorder }\end{array}$ & 162 & 39.5 & 21 & 5.1 & $/ / 1.1$ \\
\hline
\end{tabular}

\section{DISCUSSION}

This study was conducted after 6 months of exposure of traumatic events during the war on Gaza on January 2009 in which children and their families had been exposed to wide range of traumatic events. This study aimed to investigate the effect of war on children psychological wellbeing and comorbidity between post traumatic stress disorder and other behavioural problems such as attention deficit with hyperactivity, oppositional defiant disorder, and conduct disorder. In this study still children reported high number of traumatic experiences, but less than the previous study two weeks after the war [24]. After 6 months of the end of war, children still reported commonly traumatic events such as hearing the sonic sounds of the jetfighters, hearing shelling of the area by artillery, watching mutilated bodies in TV, deprivation from water or electricity during the war, and leaving home form more safe place. This is consistent with our previous studies in the area which showed similar types of traumatic events [25]. The study showed that only $25 \%$ of Palestinian children showed no post traumatic stress reactions, $25.9 \%$ of children reported one criteria (B, or $\mathrm{C}$, or $\mathrm{D}), 39.3 \%$ of children reported partial post traumatic stress disorder $(\mathrm{B}+\mathrm{C}$, or $\mathrm{B}+\mathrm{D}$, or C + D) and $9.8 \%$ of children reported full criteria for post traumatic stress disorder. This result is consistent with our previous studies which showed that Palestinian children reported from $40 \%$ to $71 \%$ psychological reactions to traumatic experiences $[24,25]$. Also, in another of Palestinian students from both the West Bank and Gaza showed that 36\% of West Bank and 35\% of Gaza Strip participants reported symptoms meeting criteria for full post traumatic stress disorder according to DSM-TR, and $12 \%$ of West Bank and $11 \%$ of Gaza Strip reported symptoms meeting criteria for partial post traumatic stress disorder. In another study of the impact of siege on
Palestinian children mental health and resilience [24], a sample of 386 children was selected from a community pole from the entire Gaza Strip. The study showed that $12.4 \%$ of children reported probable post traumatic stress disorder, 103 children were reported one Criteria (reexperiencing, or avoidance, or hyperarousal) (26.7\%), 86 of children reported two criteria-Partial post traumatic stress disorder (22.3\%), and 149 children had no post traumatic stress disorder symptoms (38.4\%). No gender differences in post traumatic stress disorder [26]. Our study revealed that $29 \%$ of children met criteria for combined type according to their parents compared to $28.3 \%$ rated by them. This is higher that our previous study [6] of Palestinian children in Gaza Strip and West Bank which showed that $8.4 \%$ of children from Gaza fulfilled the full criteria of attention deficit with hyperactivity combined type compared to $2.7 \%$ from West Bank. Also, our study was inconsistent with study aimed of this study is to identify Attention Deficit Hyperactivity Disorders among primary school children in the State of Qatar. The data revealed that 112 boys (14.1\%) and 33 girls (4.4\%) scored above the cut-off for attention deficit with hyperactivity symptoms, thus giving an overall prevalence of $9.4 \%$ [27]. In a similar study was carried out in the United Arab Emirates, which revealed an overall prevalence rate of $14.9 \%$ [28]. In an epidemiological study (Rowland et al., 2001) conducted in North Carolina among elementary school children, it was noted that $12.7 \%$ of the children met study case criteria for attention deficit with hyperactivity, based on combined teacher and parent reports [29].

Our results were inconsistent with a study aimed to assess the prevalence of DSM-III-R symptoms of attention deficit hyperactivity disorder (ADHD) and opposetional defiant disorder (ODD) in an outpatient pediatric population in Argentina; showed that 9\%, had positive scores consistent with attention deficit with hyperactivity. These children had an oppositional behavior rate of $33.3 \%$ and a grade retention rate of $30.7 \%$. Those who did not have positive scores for attention deficit with hyperactivity had a rate of $5.5 \%$ and $7.3 \%$, respectively. The mean scores for the boys on the attention deficit with hyperactivity rating scale was 17.1; the girls had a mean of 14.7 [30].

The study showed that $5.1 \%$ of children had comorbidity of post traumatic stress disorder and attention deficit disorder, $4.4 \%$ had comorbidity of post traumatic stress disorder and impulsivity-hyperactivity, and $4.4 \%$ had comorbidity of post traumatic stress disorder and attention deficit disorder, combined type. Also, $4.6 \%$ of children had comorbidity of conduct and post traumatic stress disorder and $6.1 \%$ had comorbidity of oppositional defiant disorder and post traumatic stress disorder. The overlap of attention deficit disorder, and post traumatic 
stress disorder concerns the following symptoms: irritability, excessive motor activity, concentration difficulties, impulsive behavior, and exaggerated startle responses [23], both of which may be characterized by difficulty concentrating, restlessness or irritability, and impulsivity. However, the mechanism(s) underlying this heightened risk for co-morbid illness is poorly understood. Identification of etiological factors in attention deficit with hyperactivity and psychiatric co-morbidity are topics of extant research. Recent molecular genetic studies suggest several chromosomal regions may harbor risk genes of moderate effect in attention deficit with hyperactivity, while candidate gene studies, thus far, support a likely role of dopamine-related systems in attention deficit disorder [31,32].

\section{CLINICAL IMPLICATIONS}

The results of this study of Palestinian children 6 months after the end of war on Gaza and the continuing siege of the Gaza Strip indicated that children may show symptoms of both post traumatic stress disorder-related symptoms and attention deficit disorder. Children with a high level of traumatic events seemed to have a high risk of displaying both sets of symptoms/diagnoses. The finding of post traumatic stress disorder-related symptoms and attention deficit disorder, appearing together in the same child, might be looked as indicating comorbidity. However, according to the findings of the present study, true comorbidity might not be the case because the symptoms manifested in the two disorders were so similar. Children may also have post traumatic stress disorderrelated symptoms and, because of their anxious state, show hyperactivity, attention problems, and impulsivity, this could be conceptualized as attention deficit disorder by the clinician, which in turn could impair the treatment prescribed for the children in area of war and conflict and need methods of intervention showed used, including of parents, teachers, and siblings also an important protective factor in enhancing children recovery from trauma. Programs of psychoeducation with recognized protocols including children, parents, teachers and professionals should be implemented in groups. Teachers also must be included in the intervention programs in school.

\section{REFERENCES}

[1] Palestinian Red Crescent (2008) Humanitarian suffering during the last Israeli offensive on Gaza Strip and the role of the Palestine Red Crescent society. Humanitarian duty report.

http://www.palestinercs.org/en/adetails.php?aid=18

[2] Thabet, A. and Vostanis, P. (1998) Social adversities and anxiety disorders in the Gaza Strip. Archives of Childhood Diseases, 78, 439-442. doi:10.1136/adc.78.5.439
[3] Thabet, A., Abed, Y. and Vostanis, P. (2001) The effect of trauma on Palestinian children and mothers mental health in the Gaza Strip. Eastern Mediterranean Public Health Journal, 7, 314-321.

[4] Thabet, A. and Vostanis, P. (2001) Epidemiology of psychiatric disorders in the Gaza Strip. Eastern Mediterranean Public Health Journal, 7, 403-412.

[5] Thabet, A., Abu Tawahina, A., El Sarraj, E. and Vostanis, P. (2008) Exposure to war trauma and PTSD among parents and children in the Gaza Strip. European Child \& Adolescent Psychiatry, 17, 191-199. doi:10.1007/s00787-007-0653-9

[6] Thabet, A., Al Ghamdi, H., Abdulla, T., Elhelou, M. and Vostanis, P. (2010) Attention deficit-hyperactivity symptoms among Palestinian children. Eastern Mediterranean Health Journal, 16, 259-263.

[7] August, G.J., Realmuto, G.M., MacDonald, A.W., Nugent, S.M. and Crosby, R. (1996) Prevalence of ADHD and comorbid disorders among elementary school children screened for disruptive behavior. Journal of Abnormal Child Psychology, 24, 571-595.

[8] Biederman, J., Newcorn, J. and Sprich, S. (1991) Comorbidity of attention deficient hyperactivity disorder with conduct, depressive, anxiety, and other disorders. American Journal of Psychiatry, 148, 564-577.

[9] Jensen, P.S., Hinshaw, S.P., Kraemer, H.C., Lenora, N., Newcorn, J.H., Abikoff, H.B., et al. (2001) ADHD comorbidity findings from the MTA study, Comparing comorbid subgroups. Journal of the American Academy of Child and Adolescent Psychiatry, 40,147-158. doi:10.1097/00004583-200102000-00009

[10] Rohde, L.A., Biederman, J., Busnello, E.A., Zimmermann, H., Schmitz, M. and Martins S., et al. (1999) ADHD in a school sample of Brazilian adolescents. A study of prevalence, comorbid conditions, and impairments. Journal of the American Academy of Child and Adolescent Psychiatry, 38, 716-722. doi:10.1097/00004583-199906000-00019

[11] Wilens, T., Biederman, J., Brown, S., Tanguay, S., Monuteaux, M. and Blake, C., et al. (2002). Psychiatric comorbidity and functioning in clinically referred preschool children and school-aged youths with ADHD. Journal of the American Academy of Child and Adolescent Psychiatry, 41, 262-268. doi:10.1097/00004583-200203000-00005

[12] Barkley, R.A., Murphy, K.R. and Kwasnik, D. (1996) Motor vehicle driving competencies and risks in teens and young adults with attention deficit hyperactivity disorder. Pediatrics, 98, 1089-1095.

[13] Yule, W., Udwin, O. and Murdoch, K. (1990) The “Jupiter" sinking, effects on children's fears, depression, and anxiety. Journal of Child Psychology and Psychiatry and Allied Disciplines, 31, 1051-1061. doi:10.1111/j.1469-7610.1990.tb00845.x

[14] Goenjian, A.K., Pynoos, R. and Steinberg, A.M. (1995) Psychiatric co-morbidity in children after the 1988 earthquake in Armenia. Journal of the American Academy of Child and Adolescent Psychiatry, 34, 1174-1184. doi:10.1097/00004583-199509000-00015 
[15] Bolton, D., Hill, J., O’Ryan, D., Udwin, O., Boyle, S. and Yule, W. (2004) Long-term effects of psychological trauma on psychosocial functioning. Journal of Child Psychology and Psychiatry, 45, 1007-1014. doi:10.1111/j.1469-7610.2004.t01-1-00292.x

[16] Carrion, V., Weems, C., Ray, R. and Reiss, A. (2002) Toward an empirical definition of pediatric PTSD, the phenomenology of PTSD symptoms in youth. Journal of the American Academy of Child \& Adolescent Psychiatry, 41, 166-173. doi:10.1097/00004583-200202000-00010

[17] Ford, J.D., Racusin, R., Ellis, C.G., Daviss, W.B., Reiser, J. and Fleischer, A., et al. (2000) Child maltreatment, other trauma exposure, and posttraumatic symptomatology among children with oppositional defiant and attention-deficit/ hyperactivity disorder. Child Maltreatment, 5, 205-217. doi:10.1177/1077559500005003001

[18] Weinstein, D., Staffelbach, D. and Biaggio, M. (2002) Attention-deficit/hyperactivity disorder and posttraumatic stress disorder, differential diagnosis in childhood sexual abuse. Clinical Psychology Review, 20, 359-378. doi:10.1016/S0272-7358(98)00107-X

[19] Famularo, R., Fenton T., Kinscherff, R. and Augustyn, M. (1996) Psychiatric comorbidity in childhood posttraumatic stress disorder. Child Abuse and Neglect, 20, 953961. doi:10.1016/0145-2134(96)00084-1

[20] Glod, C.A. and Teicher, M.H. (1996) Relationship between early abuse, posttraumatic stress disorder, and activity levels in prepubertal children. Journal of the American Academy of Child and Adolescent Psychiatry, 35, 1384-1393. doi:10.1097/00004583-199610000-00026

[21] Riggs, P.D., Baker, S., Mikulich, S.K., Young, S.E. and Crowley, T.J. (1995) Depression in substance-dependent delinquents. Journal of the American Academy of Child and Adolescent Psychiatry, 34, 764-771. doi:10.1097/00004583-199506000-00017

[22] Pynoos, R.S., Rodriquez, N., Steinberg, A., Stuber, M. and Frederick, C. (1998) The UCLA posttraumatic stress reaction index for DSM-IV. UCLA Trauma Psychiatric Program, Los Angeles.

[23] American Psychiatric Association (2000) Diagnostics and statistical manual of mental disorders. 4th Edition, American Psychiatric Association, Washington DC.
[24] Thabet, A.A., Abu Tawahina, A., El Sarraj, E. and Vostanis, P. (2012) Trauma, grief, and PTSD in Palestinian children victims of war on Gaza. Arabpsynet E. Journal.

[25] Thabet, A.A., Abu Tawahina, A., El Sarraj, E. and Vostanis P. (2007) Children exposed to political conflict, implications for health policy. Harvard Health Policy Review, 8, 47-57.

[26] Abdeen, Z., Qasrawi, R., Nabil, S. and Shaheen M. (2008) Psychological reactions to Israeli occupation, findings from the national study of school-based screening in Palestine. International Journal of Behavioral Development, 32, 290-297. doi:10.1177/0165025408092220

[27] Bener, A., Al Qahtani, R. and Abdelaal, I. (2006) The prevalence of ADHD among primary school children in an Arabian society. Journal of Attention Disorders, 10, 77-82. doi:10.1177/1087054705284500

[28] Bu-Haroon, A., Eapen, V. and Bener, A. (1999) The prevalence of hyperactivity symptoms in the United Arab Emirates. Nordic Journal of Psychiatry, 53, 439-442. doi:10.1080/080394899427683

[29] Rowland, A.S., Umbach, D.M., Catoe, K.E., Stallone, L., Long, S., Rabiner, D., et al. (2001) Studying the epidemicology of attention deficit hyperactivity disorder, screening method and pilot results. Canadian Journal of Psychiatry, 46, 931-940.

[30] Michanie, C., Kunst, G., Margulies, D.S. and Yakhkind, A. (2007) Symptom prevalence of ADHD and ODD in a pediatric population in argentina. Journal of Attention Disorder, 11, 363-367. doi:10.1177/1087054707299406

[31] Ogdie, M.N., Fisher, S.E., Yang, M., Ishii, J., Francks, C., Loo, S.K., Cantor, R.M., McCracken, J.T., McGough, J.J, Smalley, S.L., et al. (2004) Attention deficit hyperactivity disorder, fine mapping supports linkage to 5p13, 6q12, 16p13, and 17p11. The American Journal of Human Genetics, 75, 661-668. doi:10.1086/424387

[32] Hebebrand, J., Dempfle, A., Saar, K., Thiele, H., Herpertz-Dahlmann, B., Linder, M., Kiefl, H., Remschmidt, H., Hemminger, U. and Warnke, A., et al. (2006) A genome-wide scan for attention-deficit/hyperactivity disorder in 155 German sib-pairs. Molecular Psychiatry, 11, 196-205. doi:10.1038/sj.mp.4001761 